\title{
Experimental set for testing methods of industrial wastewaters treatment with the use of flotation techniques
}

\author{
Sławomir Żak ${ }^{\mathrm{a}}$, Lech Zabłocki ${ }^{\mathrm{b}}$ \\ ${ }^{a}$ Department of Chemical Technology and Engineering, University of Technology and Life Sciences, 3 Seminaryjna Street, \\ 85-326 Bydgoszcz, Poland \\ ${ }^{b}$ Department of Research and Implementation, Projprzem-Eko sp. z o.o., l Osiedlowa Street, 89-300 Zamość n. Bydgoszcz, Poland
}

\begin{abstract}
This paper presents a set for testing industrial wastewaters in technical scale using physicochemical methods of their pretreatment at the source of their origin with flotational precipitation of flocculated and thickened dispersed fractions. The installation constructed on a mobile pallet of capacity up to $1.0 \mathrm{~m}^{3} / \mathrm{h}$ is equipped with a central, cylindrical-conical process reactor with a slow-speed frame agitator (or with an optional flotator and a surface flotate skimmer), tubular reactors where chemical reagents are dispensed from their preparation and dosing stations, as well as with the process nodes to conduct flotation techniques with induced air (IAF) and/or dissolved air (DAF) according to the own invention or with the assistance of oxidation (OxIAF and/or OxDAF). Using this test set, different methods of physicochemical pretreatment can be optimised by means of i.a.: coagulation, chemical precipitation or deep oxidation and final separation of the dispersed phases with mentioned flotation techniques supported by oxidation with e.g. hydrogen peroxide.
\end{abstract}

Keywords: mobile testing set; industrial wastewater pretreatment; OxIAF and OxDAF type flotation.

\begin{tabular}{|ll|}
\hline Nomenclature \\
IAF & induced air flotation \\
DAF & dissolved air flotation \\
OxIAF & oxidised induced air flotation \\
OxDAF & oxidised dissolved air flotation \\
COD & chemical oxygen demand $(\mathrm{mg} / \mathrm{l})$ \\
BOD5 & biochemical oxygen demand $(\mathrm{mg} / \mathrm{l})$ \\
EE & etheric extract $(\mathrm{mg} / \mathrm{l})$ \\
TP & total phosphorus $(\mathrm{mg} / \mathrm{l})$ \\
TN & total nitrogen $(\mathrm{mg} / \mathrm{l})$ \\
\hline
\end{tabular}

\section{Introduction}

While developing detailed treatment techniques of industrial wastewater, a key aspect is a correct determination of the operation sequence of essential process reactors and their efficiencies [1-3]. At the stage of design work in a final selection of processing configuration of target technology, it is important whether the processes are to be conducted with the use of batch reactors or flow reactors under conditions of continuous treatment. In the technology of industrial wastewaters, many operations and unit processes tested in laboratory scale have to face the problem of similitude at the stage of their implementation in real practical application [1-8]. The procedure of determining the parameters that are significant for the tested process in laboratory scale must be deeply verified and re-optimised while implementing the operations in real, industrial installations in full scale [9-12]. In the design practice, it is necessary not to anticipate the design work for the enlarged scale tests of technological size (quarter- and semi-technical scales), which may induce necessary corrections of projects or/and essential technological modifications even at the final phase of the target system erection. A detailed schedule of semi-technical tests depends on a size of target plant [9]. It is often necessary to verify the process while testing it under variable circumstances of technological scales, primarily - the basic physicochemical and physicorheological conditions. For example, the results of tests in laboratory scale using the separation of flotational precipitation belong to a

Corresponding author: Sławomir Żak. E-mail address: zak@utp.edu.pl

http://dx.doi.org/10.3846/enviro.2014.101

(C) 2014 The Authors. Published by VGTU Press. This is an open-access article distributed under the terms of the Creative Commons Attribution License, which permits unrestricted use, distribution, and reproduction in any medium, provided the original author and source are credited. 
category of technical issues that are to be verified earlier, before their implementation on full-scale industrial installations. In most cases, the verification consists in correcting the values for the parameters of significant impact on the capacity of treatment operations and optimising their effect on the whole process of effluent treatment [9-15].

This study presents a testing set designed to investigate physicochemical pretreatment methods of industrial wastewaters that can operate in different working variants, in sequence and in wastewater continuous flow.

\section{Experimental part}

The lack of literature data concerning semi-technical research forced us to develop presented here investigatory installation and to work out our own specific methodologies for different types of industrial wastes which are generally based on years of deepening our knowledge on wastewater processing gained gradually in practice of implementing and operating the treatment processes. The building of the experimental system was preceded by the many-year research in laboratory scale, the aim of which was to set up the simplest and, at the same time, the most effective mobile module unit that would be an autonomous, small system of physicochemical pretreatment plant for testing the purification methods directly at a source of generating raw industrial wastewaters or pumped at a site of their storage and equalization. Such operationally configured installation was to verify the test results obtained in laboratory scale that preceded the design stages of operations and the technological plant in target full technological scale by verifying the worked out methods on actual flows of the postproduction effluents.

\subsection{Technological design and configuration of the mobile testing set}

The mobile experimental installation to test physicochemical methods for pretreating industrial wastewaters (Fig. 1) was configured in such a way to be the last link in the whole cycle of developing technologies used to treat wastewaters with the capacity at a dozen to several hundred cubic meters per day. A major advantage of this system is its ability to work in two processing options: in batch/sequence operation and continuous-flow operation. The testing set was built on a mobile pallet and consists of the following processing nodes:

a) a reactor node (central cylindrical-conical reactor equipped with a low-speed frame agitator or with an optional flotator expansion chamber equipped with surface scraper flotate skimmer and two processing independent tubular reactors);

b) a flotating node (pressure saturation tank and/or a saturation and dispersion set acc. to own invention [16]);

c) a control \& optimising node;

d) a node for preparation and dispensing reagents.

In a version of continuous operation of the experimental installation, raw effluents, after their thorough averaging, are directed onto a tube reactor (Fig. 1c), where the process reagents are introduced. In this mode of operation, the cylindricalconical volume of tank acts as an expansion chamber of the flotation system with simultaneous separation of dispersed phases using surface skimmer of the flotate mass. In a batch option of the operation, raw effluents are directed to a first tube reactor where processing reagents are dosed (all or their part). The second tube reactor is linked with the central reactor between which mixing and averaging wastewaters are carried out by cross flows. Flocculant is metered directly into the central reactor at the final phase of the effluent pretreatment process. Depending on the needs, the operation of effluent averaging is additionally enhanced by a stream of air, supplied directly from the air compressor or from the plant compressed air supply system, injected into a cone of the bottom part of the central reactor. (In the first operational option, the IAF type flotation is also enhanced.) The author's original way of flotation is conducted in the aeration modules connected in series (Fig. $1 \mathrm{~b}$ and d) consisting of permanently coupled concentric, cylindrical membrane aeration devices and flow cylindrical external chambers, where wastewater is introduced with flow speeds within $0.05-0.5 \mathrm{~m} / \mathrm{s}$ (specific for each type of the pretreated effluents). Generally, the contact time of air (introduced in air pressure range: 50-600 kPa) with wastewater ranges within 10-150 seconds under the conditions of cocurrent and countercurrent flow [16]. The testing installation is equipped with analytical kits to monitor $\mathrm{pH}$ and redox potential in different processing nodes. 


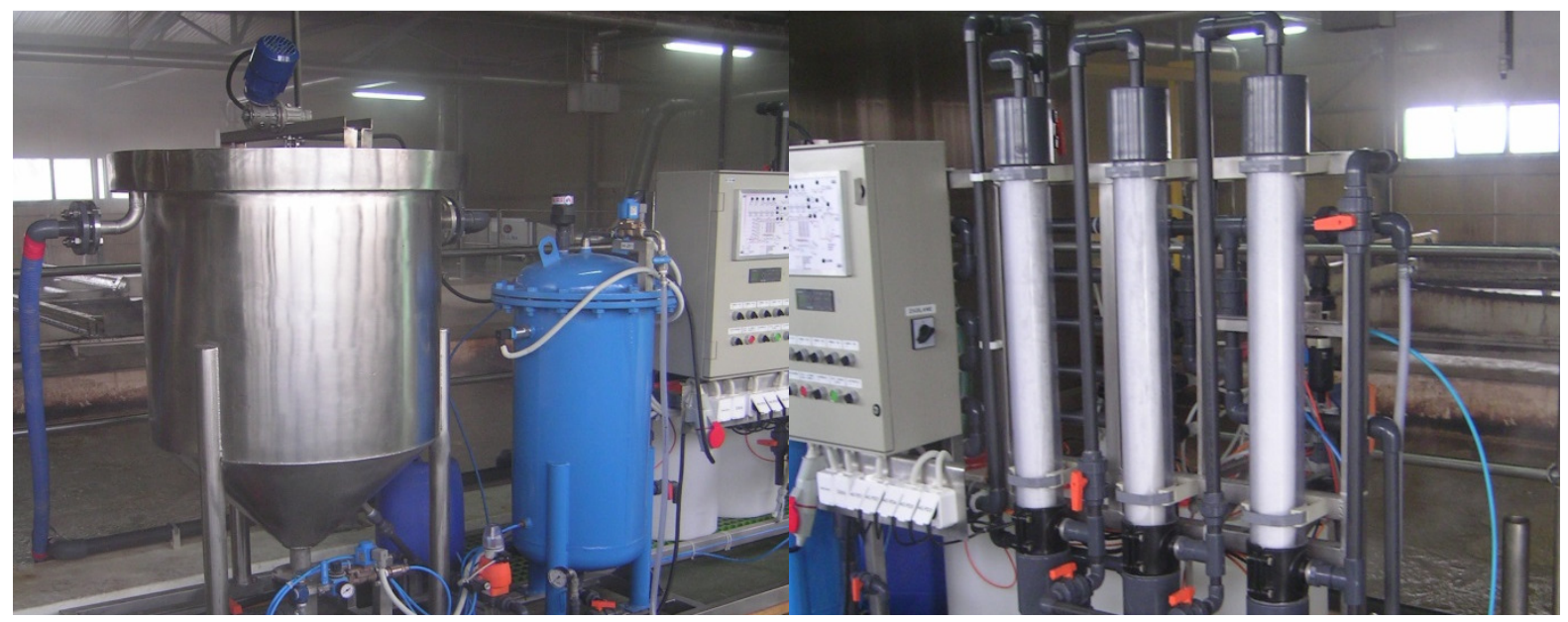

a)

b)

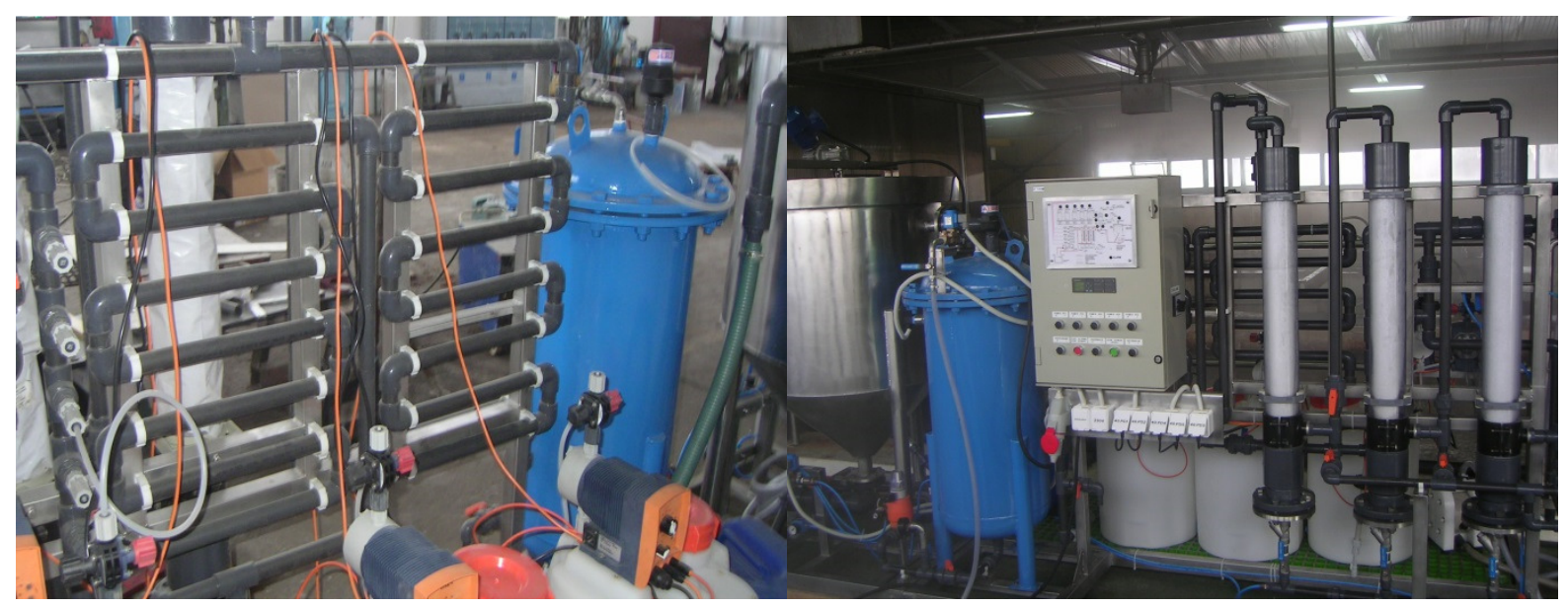

c)

d)

Fig. 1. View of the infrastructure equipment of mobile testing set, where: (a) in the foreground: a cylindrical-conical process reactor (in the background: a saturation tank and a control cabinet), (b) author's saturation-dispersion set [16], c) tube reactors, d) view of the testing palette with its processing elements

\section{Results and discussion}

Usually, in the experiments in semi-technical scale that precede essential stages of the design, a few variants of the process are tested to verify the flow diagram worked out in laboratory scale, for which the most favourable process parameters have been achieved. This option provides the basis for further design of physicochemical pretreatment of industrial wastewater. The correct project and construction of the plant should be based on the experimental data obtained in semi-technical scale. A purpose of tests in this scale is to define values of key parameters for the effective effluent purification (the level of doses for process reagents, duration times for effluent averaging and for the occurrence of essential chemical reactions, times for conducting effective stages of phase separation: precipitation, flotation etc., conditions and variation scopes of $\mathrm{pH}$ and redox potential). This important research phase is also to identify possible adjustments in some technological nodes for further improvement of the target parameters of the potential installation performance in full technological scale [3], [8], [12]. The semi-technical scale is also a last link of the whole cycle of tests during the development of a specific wastewater treatment technology using the selected flotation variant for separating dispersed phases. The exemplary industrial wastewaters show their treatment technologies with full process verification using the presented testing set (Table 1).

A primary drawback of the technological tests in laboratory scale is the necessity of using the wastewater with chemically or biologically converted composition with reference to fresh raw effluents. It concerns especially the loads of natural organic wastewater containing poly- and oligosaccharides and proteins. These loads are easily degradable under natural contagion with microbes and fungi and undergo spontaneous fermentation and saprogenic processes, which results in fast increase in soluble pools of e.g. COD and BOD [17-20] with reference to their dispersed pools. A frequent phenomenon accompanying those processes is also the appearance and fixation of emulsive character of the wastewater, especially for fatty substances [21]. That type of effluents require adequate fixation at the stage of random sampling for testing purposes, which is often linked with the chemical enrichment of the pool of load. In laboratory-scale tests, it often leads to inadequate doses of chemical reagents indicated in the developed methods of physicochemical pretreatment, perturbations in testing the processes of phase separation (e.g. sedimentation and flotation) and in the assessment of susceptibility to flocculation. For many types of effluents produced in the industrial sectors that use natural raw materials, 
we came across such problems while conducting tests in different technical scales. An example of the selected types of wastewaters, the aspects of which are related with the problem of similitude and the need to re-examine key process parameters, are presented in Table 1. In the cited cases, the use of the testing installation much facilitated and shortened the time of selecting optimum methods for wastewater pretreatment (listed in the table) and strongly helped with implementation work, and, which is the most important, provided the required ecological effect for the technologies implemented in full commercial scale.

Table 1. Examples of selected industrial wastewaters for which methods of physicochemical pretreatment have been developed to be applied for verifying the process in semi-technical scale of the presented here testing set

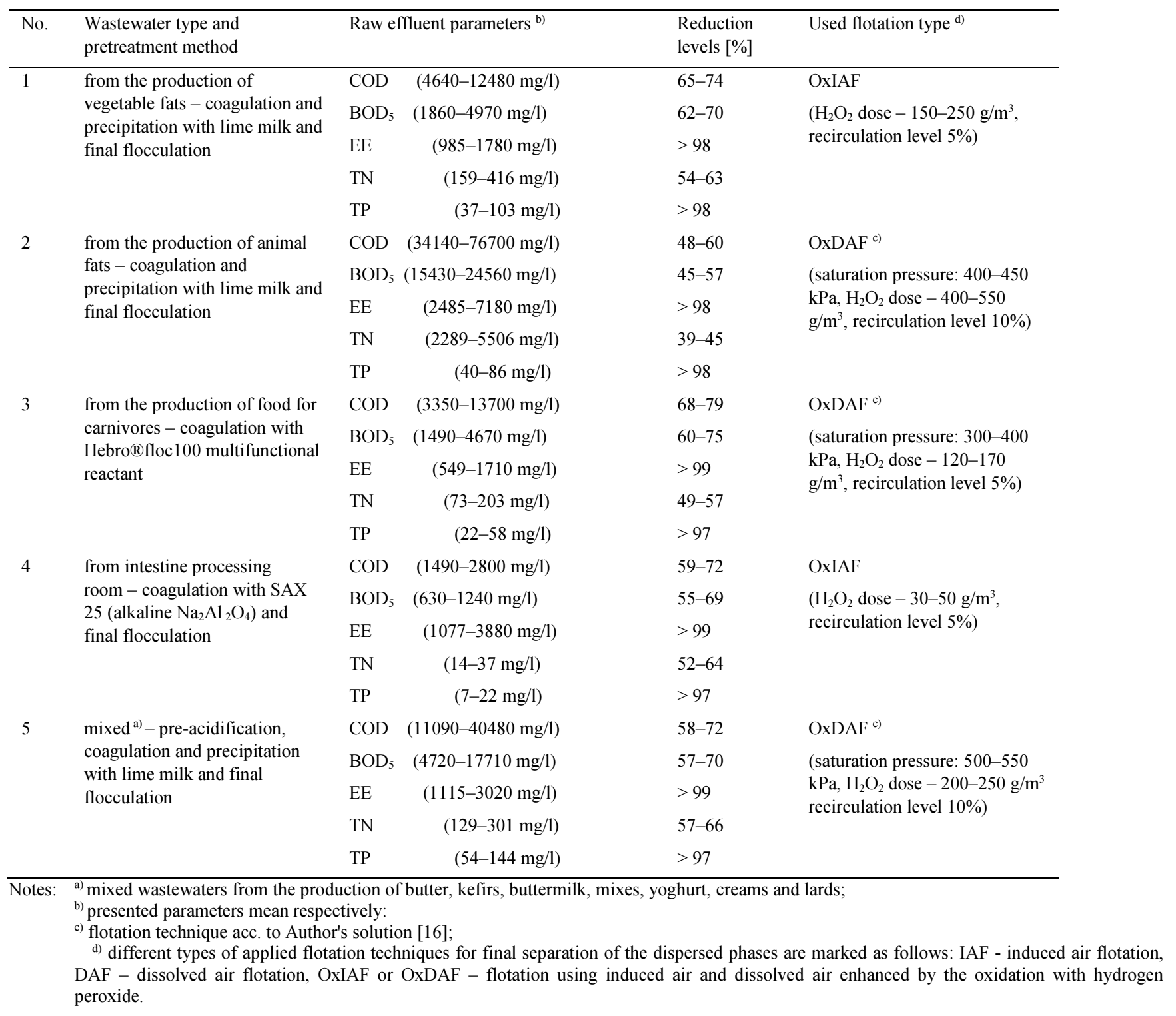

\section{Conclusion}

The mobile testing set under discussion made it possible to develop and implement processes for physicochemical pretreatment of wastewaters from fat industry - the installation of physicochemical pretreatment plant based on the use of flotation technique according to Author's invention has been made for ZT Kruszwica S. A. in Kruszwica (Poland). The second installation with the discussed flotation technique has been constructed for the Production Factory P. H. U. JAGR in Warlubie (Poland) that purifies mixed industrial wastewaters from the production lines of butter, kefirs, buttermilk, mixes, yoghurt, creams and lard, as well as HoReCa products. Both industrial installations are used to purify quantities of waste water at $450-550 \mathrm{~m}^{3}$ per day. 


\section{Acknowledgements}

Presented here testing installation and the works on developing the technology for the pretreatment of industrial wastewaters were aided by funds of the target project ROW-300-2003 implemented by the Centre of Innovation of the Polish Federation of Engineering Associations - NOT.

\section{References}

[1] Woodard \& Curran Inc.: Part 7. Methods for Treating Wastewaters from Industry Industrial Waste Treatment Handbook (2* ed.), 2006, 149-334. http://www.sciencedirect.com/science/article/pii/B9780750679633500096

[2] Woodard \& Curran Inc.: 10. Wastes from Industries (Case Studies), Industrial Waste Treatment Handbook (2* ed.), 2006, $409-496$. http://www.sciencedirect.com/science/article/pii/B9780750679633500126

[3] Towler, G.; Sinnott, R. K. 2013. Chapter 15 - Design of Reactors and Mixers. Chemical Engineering Design (2* ed.), 631-751. http://www.sciencedirect.com/science/article/pii/B9780080966595000158

[4] Molinos-Senante, M.; Hernández-Sancho, F.; Sala-Garrido, R. 2012. Economic feasibility study for new technological alternatives in wastewater treatment processes: a review, Water Science and Technology 65(5): 898-906. http://dx.doi.org/10.2166/wst.2012.936

[5] Arvanitoyannis, I. S.; Ladas, D. 2008. Meat Waste Management: Treatment Methods and Potential Uses of Treated Waste. Waste Management for the Food Industries 765-800. http://www.sciencedirect.com/science/article/pii/B9780123736543500158

[6] Arvanitoyannis, I. S.; Varzakas, T. H. 2008. Fruit/Fruit Juice Waste Management: Treatment Methods and Potential Uses of Treated Waste. Waste Management for the Food Industries (), 569-628. http://www.sciencedirect.com/science/article/pii/B9780123736543500122

[7] Silva, T. F. C. V.; Silva, M. E. F.; Cunha-Queda, A. C.; Fonseca, A.; Saraiva, I.; Boaventura, R. A. R.; Vilar, V. J. P. 2013. Sanitary landfill leachate treatment using combined solar photo-Fenton and biological oxidation processes at pre-industrial scale, Chemical Engineering Journal 228: 850-866. http://dx.doi.org/10.1016/j.cej.2013.05.060

[8] Arvanitoyannis, I. S.; Kassaveti, A. 2008. Olive Oil Waste Management: Treatment Methods and Potential Uses of Treated Waste. Waste Management for the Food Industries (, 453-568. http://www.sciencedirect.com/science/article/pii/B9780123736543500110

[9] Aragonés-Beltrán, P.; Mendoza-Roca, J. A.; Bes-Piá, A.; García-Melón, M.; Parra-Ruiz, E. 2009. Application of multicriteria decision analysis to jartest results for chemicals selection in the physical-chemical treatment of textile wastewater, Journal of Hazardous Materials 164(1): 288-295. http://dx.doi.org/10.1016/j.jhazmat.2008.08.046

[10] Müller, M.; Kasaka, Y.; Müller, D.; Schomäcker, R.; Wozny, G. 2013. Process design for the separation of three liquid phases for a continuous hydroformylation process in a miniplant scale, Industrial \& Engineering Chemistry Research 52: 7259-7264. http://dx.doi.org/10.1021/ie302487m

[11] Kriipsalu, M.; Marques, M.; Maastik, A. 2008. Characterization of oily sludge from wastewater treatment plant flocculation-flotation unit in a petroleum refinery and its treatment implications, Journal of Material Cycles Waste Management 10(1): 79-86. http://dx.doi.org/10.1007/s10163007-0188-7

[12] Zeng, G.; Jiang, R.; Huang, G.; Xu, M.; Li, J. 2007. Optimization of wastewater treatment alternative selection by hierarchy grey relational analysis, Journal of Environmental Management 82(2): 250-259. http://dx.doi.org/10.1016/j.jenvman.2005.12.024

[13] Anzalone, A.; Bewtra, J. K.; Ali, H. I. 2014. Physical and Chemical Treatment of Wastewater, in Encyclopedia of Environmental Science and Engineering (6 ed.).

[14] Scott, K. 1998. Section 11. Industrial waste water and effluent treatment. Handbook of Industrial Membranes (2 ed.), 575-629. http://dx.doi.org/10.1016/B978-185617233-2/50014-3

[15] De Clercq, B.; Coen, F.; Vanderhaegen, B.; Vanrolleghem, P. A. 1999. Calibrating simple models for mixing and flow propagation in waste water treatment plants, Water Science and Technology 39(4): 61-69. http://dx.doi.org/10.1016/S0273-1223(99)00057-8

[16] Żak, S.; Zabłocki, L. Way of conducting the flotation. 2012. Polish Patent 211742 B1 (in Polish).

[17] Rubio, J.; Souza, M. L.; Smith, R. W. 2002. Overview of flotation as a wastewater treatment technique, Minerals Engineering 15(3): 139-155. http://dx.doi.org/10.1016/S0892-6875(01)00216-3

[18] Fakhru'l-Razi, A.; Pendashteh, A.; Abdullah, L. C.; Biak, D. R. A.; Madaeni, S. S.; Abidin, Z. Z. 2009. Review of technologies for oil and gas produced water treatment, Journal of Hazardous Materials 170(2-3): 530-551. http://dx. doi.org/10.1016/j.jhazmat.2009.05.044

[19] Ahmad, A.; Ghufran, R.; Wahid, Z. A.: 2012. Effect of cod loading rate on an upflow anaerobic sludge blanket reactor during anaerobic digestion of palm oil mill effluent with butyrate, Journal of Environmental Engineering and Landscape Management 20(4): 256-264. http://dx.doi.org/10.3846/16486897.2012.656647

[20] Matikevičienè, V.; Grigiškis, S.; Levišauskas, D. 2012. Technology for treatment of lipid-rich wastewater and pipelines clogged by lipids using bacterial preparation, Journal of Environmental Engineering and Landscape Management 20(1): 49-57. http://dx.doi.org/10.3846/16486897.2012.662747

[21] Fan, L.; Mao, Z.; Wang, Y. 2005. Numerical simulation of turbulent solid-liquid two-phase flow and orientation of slender particles in a stirred tank, Chemical Engineering Science 60(24): 7045-7056. http://dx.doi.org/10.1016/j.ces.2005.06.030 